\title{
How people speak about autonomous cars - an analysis of internet discussions in Czech Republic
}

\author{
PETR ZÁMEČNÍK ${ }^{\mathrm{a}}$, DARINA HAVLÍČKOVÁ ${ }^{\mathrm{b}}$, ADAM GREGOROVIČb ${ }^{\mathrm{b}}$, PETR DĚCKÝ ${ }^{\mathrm{b}}$, SÁRA KLEČKOVÁ \\ a. Katedra Psychologie, Filosofická fakulta, Univerzita Palackého, Kř́žžovského 10, Olomouc 77180, Česká republika \\ b. CDV - Transport Research Centre, Lisenska 33a, 63600 Brno, Czech Republic
}

KEYWORDS: Automated vehicles, autonomous vehicles, driverless cars, internet discussions

ABSTRACT: This study aims to explore and to define the main topics and concerns regarding the issue of autonomous vehicles in the Czech population. Further, the change of these topics throughout time is explored. To do this, the qualitative content analysis of comments below news articles concerning autonomous vehicles on popular Czech Internet websites was performed to extract main discussed topics.

With a huge development of autonomous vehicles (AVs) and its technology, the question of successful implementation arises. The acceptance of this technology by the end users stands for an important factor of the implementation. For this, general attitudes toward autonomous vehicles and various concerns of people provide important information. The aim of this paper is to explore main topics and concerns regarding the issue of autonomous vehicles in the Czech population. The qualitative analysis of internet discussions beneath news articles about autonomous vehicles (AVs) on popular Czech news portals was performed. Two separated data collections were performed for a total of 17 articles from July 2014 to February 2020 to address the changes in attitudes through time. Content analysis revealed a general skepticism and a large number of concerns. The negativity and fear of the Czech discussants stemmed mainly from insufficient knowledge of the topic. Content analysis revealed main topics concerned the introduction of autonomous mobility into general practice in terms of time (when), experience (especially previous negative experience with elements of control automation), and analogy (comparisons to other modes of transport). Other important topics addressed driving pleasure, (dis)trust of manufacturers, legal and ethical questions about $\mathrm{AV}$, risk of hacker attacks, reactions of drivers of conventional vehicles, carsharing, financial use of AV, manual takeover, application of AV only for some modes of transportation (e.g., freight transport), and a difficulty of introducing AVs into the Czech environment. In contrast to foreign opinion polls, there were no topics related to privacy and the misuse of personal data. It was not possible to find socio-demographic variables from the discussion threads, but information about the preference of news portals by older age groups was obtained from the data on the monitored portals. Assuming that authors of the comments were older people, the negative attitude towards AV corresponds to the current literature. In order to ensure representative data, it will be necessary to identify socio-demographic variables and the extension of the analyzed discussion threads to social networks as part of further research. Without these preconditions, it will be difficult to determine accurate evaluations and possibly to create an educational campaign for the general public focused on autonomous mobility.

\section{INTRODUCTION}

New technology in the form of autonomous mobility promises to help transportation, particularly by reducing accidents and increasing traffic flow (Gao, Hensley, \& Zielke, 2014; van Arem, van Driel, \& Visser, 2006). Autonomous technology can be used even by people who cannot drive, whether due to young age, a handicap, or even because of being under the influence of alcohol. Also, being able to do different tasks instead of driving could make travel more efficient and attractive.

Autonomous vehicles discussed in this study are defined as level 5 automated vehicles etc. fully autonomous vehicles without need for human driver according to SAE classification (SAE, 2019). The opinion of end users is one of the most important factor for introducing new technology, as it provides the opportunity to assess their willingness to use it. The technology may seem useful at first glance, but if the customer is not willing to pay for it or is not able to use it, that technology may not be established and could even disappear. In history, a similar fate befell for example supersonic commercial flights by Concorde aircraft which, despite considerable speed, were abandoned (McFadden, 2017). More recently, the revolutionary "smart" Google Glass and wearable technology (e.g., smart watches) have failed. One of the reason why Google Glass have failed was the end users' concerns about health and safety but also about its appearance (Doyle, 2016).
It can be expected that end users will play an important role in the real-world implementation of AVs. Many studies have recently appeared to seek opinions of the public regarding autonomous technology. These studies present useful information about user concerns that could prevent the wide adoption of AV. One of the largest study is the Global Automotive Consumer Study form 2019 which interviewed 25,000 customers from 20 countries (Deloitte, 2019). This study reported user's opinions of AV safety have worsened significantly in recent years. Respondents themselves attribute a great deal of this mistrust to AV accidents, which have been discussed in the media. Users are also becoming less confident about the ability of traditional car brands to bring fully autonomous vehicles to market and they demand more regulation of AVs by governments. There are also concerns about data sharing and security. This, along with concerns about accidents, was shared by British respondents in a public opinion poll which found $46 \%$ thought that AV would not be safe (Flinders, 2017). Similar results were obtained by a study in the United States, where there was also an decrease in trust in AV. Previously, 73\% of American adults (up from $63 \%$ ) said they would be afraid to use an AV. The authors explained this mistrast due the influence of AV accidents that had appeared in the media (AAA Newsroom, 2018). In addition to the above-mentioned concerns, users often had concerns about liability and hacker attacks (Bansal et al., 2016; Schoettle \& Sivak, 2014a). 
Studies show there are differences in opinions on AVs depending on demographic characteristics. For example, Schoettle and Sivak (2014a; 2014b) found US respondents when compared to respondents from the United Kingdom and Australia were more concerned about using AVs, the privacy of their data, interacting with non-automated vehicles, the vehicle not driving as well as humans, and not having the option to manual take-over. In contrast, respondents from China and India had more initial positive opinions about AVs and they were willing to pay more for the technology than respondents from the US, UK, and Australia. The research by Kyriakidis et al. (2015) suggests data transmission concerns could be more likely to affect higher-income countries. A study culturally close to Czech environment was presented by König and Neumayr (2017). They interviewed 489 respondents from 33 countries, $75 \%$ of whom were from Austria. The most common cause of concern for the respondents were legal problems, closely followed by fears of hacker attacks and a general lack of confidence in the operation of the new technology. On the contrary, the least important concerns were threat of job losses and the risk that AVs would not drive as well as humans. Authors also identified opportunities to increase confidence in AVs. The best option was to be able do the manual take-over whenever the driver wanted. People over the age of 60 , and women in particular, described this option as the most effective. Furthermore, the offer of free test drives seemed to be an effective option which was most appreciated by respondents who do not use a car. Respondents across all categories also indicated that they would like detailed information about AV in dealerships. Furthermore, most respondents did not support tax relief, the allocation of special lanes, or the opportunity to actively participate in the development of AV. There are also data available from the Czech population. Cultural differences have been demonstrated and, with it, the importance of examining concerns for various demographic characteristics (Gabrhel, Ježek, \& Havlíčková, 2019). Czech respondents were concerned a lot about the inability of AV to adequately respond to unexpected situations and about the failures of $\mathrm{AV}$ systems and its effect on road safety. They did not show much concern about the legal aspects of $\mathrm{AV}$ use or the private nature of the data, as is the case especially with respondents in the US (Gabrhel, Ježek, \& Havlíčková, 2019).

Smith and Anderson (2017) also focused on demographic characteristics of the interviewees and found more interest among men (compared to women), people under 50 (compared to older people), university students (compared to respondents without an university education), and urban dwellers (as opposed to those who live in rural areas). Nielsen and Haustein (2018) found similar results in an online survey of the Danish population. Based on their analysis, the total number of 3,040 respondents was divided into three groups: skeptics (38\%), enthusiasts (25\%), and neutrals (37\%). The "skeptics" were older and car-dependend people who mostly lived in less populated areas.

Other studies suggest especially the younger generation born between 1980-2000 (the so-called Millennials or Generation $\mathrm{Y}$ ) has the most positive relationship to $\mathrm{AV}$ and the smallest concern about this technology (Deloitte, 2019; AAA Newsroom, 2018). It is a generation that grew up with modern technology, especially the Internet, which they often use as their primary source of information (Kilian, Hennigs, \& Langner, 2012). This is one of reasons showing that the Internet could be an appropriate source for information about AV concerns. So far, we are aware of one study used this kind of content analysis, namely the analysis of AV comments on YouTube videos (Li, Lin., Choi, Fu, Gong, \& Wang, 2018). However, this study does not offer any clear results regarding views about $\mathrm{AV}$, but rather only a description of the dataset and its possibilities from the point of view of Natural Language Processing.
Previously mentioned literature showed it is useful to examine the concerns of AV and that differences depend upon nationality and other demographic characteristics. We also know that a large proportion of important AV supporters use the Internet as a primary source of information, unlike other generations. An analysis of the concerns on the Internet is therefore offered as a suitable form of research. In addition, we know that most of the above-mentioned studies have been conducted in the form of (online) questionnaires that have limitations, such as lower returns, uncertainty about data validity, and less data richness (Kelley, Clark, Brown, \& Sitzia, 2003; Wright, 2005). We will try to bridge these shortcomings by analyzing internet discussions.

We aim to explore and to define main topics and concerns regarding the issue of autonomous vehicles in the Czech population. Further, the change of these topics throught the time was explored. To do this, the qualitative content analysis of comments below news articles concerning autonomous vehicles on popular Czech Internet websites was performed to extract main discussed topics. We collected data from news articles from two timeframes: $2014-2018$ and $2018-2020$ for assessing possible changes in concerns of Czech public.

\section{Research Questions:}

1. What are main topics and concerns regarding autonomous vehicles on the Czech internet?

2. Is the view on AVs changing through the time among Czech public?

\section{METHODOLOGY}

Current discussions under internet news articles about AVs were analyzed. In total, two analyses of 17 internet discussions were performed in two different periods, with an interval of one and a half year. The first wave of the collection took place in October 2018 and included seven articles from July 2014 to June 2018. The second wave took place in April 2020 and included an analysis of 10 articles from November 2018 to February 2020. The aim of content analysis was to find out what AV topics arose and whether there are different trends between the two periods.

The qualitative analysis of discussions on a particular topic under internet articles is a challenging but very relevant source of data. The main advantage of this methodology is the access to authentic opinions of population. In comparison to survey methods, Internet discussions are less biased by people's self-stylisation. On the other hand, there is very limited opportunity to discover discussant's basic sociodemographic characteristics, such as age, gender or education. The Internet environment is quite anoinymous, which allows people more authentic comments.

In both cases, the keywords "autonomous vehicles" and "discussion" were used to search for news articles on internet search engines with well-developed discussions among readers. The result of the search was primarily popular educational websites dedicated to motoring (e.g., autorevue.cz; auto.cz; elektrickevozy.cz; auto.idnes.cz), or other related areas (e.g., ekonomika.idnes.cz; penize.cz; svethardware.cz). References to articles with relevant discussions are placed in Appendix A. To include the article discussion to collection, it had to contain at least ten comments. The obtained texts were then processed with a qualitative analysis, specifically by means of a content analysis.

\begin{tabular}{lcc}
\hline & Publication date of articles & Number \\
\hline 1st analysis & July 2014 - June 2018 & 7 \\
2nd analysis & November 2018 - February 2020 & 10 \\
\hline
\end{tabular}

Table 1: Numbers of articles in 2 analyses 


\section{RESULTS}

As mentioned above, the collection of articles included the keywords "autonomous vehicle". As we found out from the analysis of discussions but also from the content of the articles, people do not discriminate well between the terms "autonomous" and "automated" vehicles. It seems that discussants do not have sufficient knowledge about different levels of automation. Mostly, writers of articles and also discussants used the term "autonomous vehicles" for various levels of automation - for the first types of available automated cars with the demand of manual take-over, as well for the fully autonomous vehicles available in far future.

The analyses of the texts revealed several of the most frequently discussed topics and concerns which are described in detail below. The list of the main topics include: Time prediction for the development of AVs, Prediction based on negative experience, Prediction based on analogy, (Dis)trust of manufacturers, Driving pleasure, Questions arising from the us of AVs, Risk of AV software infection, Joint operation, Carsharing, Financial Complexity, Manual take-over, AVs used only to some modes of transportation, and Difficulty of introducing $A V$ in the Czech republic. A comparison of the second and first analysis showed almost perfect agreement on the topics discussed. Topic Trust in manufacturers appeared only in the second analysis and only this one can be considered as a new topic. Furthermore, by comparison there were several shifts within the same topics. Overall, the second analysis which was carried out on more recent data, revealed more professional and technical discussions including for example the topic of autopilot functionality in aircraft. Although the discussants seemed to be more informed about the topic, they often held conflicting opinions and came into conflict. In both analyses, the most common topic were various estimations for the development of AVs, with a predominance for skeptical opinions which strengthened slightly in the second analysis. We provide more detailed description of main topics and subtopics in the next section.

\section{List of Topics}

- Time prediction for the development of AVs

- Prediction based on negative experience

- Prediction based on analogy

- (Dis)trust of manufacturers - only in second analysis

- Driving pleasure

- Questions arising from the use of AVs

- Risk of AV software infection

- Joint Operation

- Carsharing

- Financial complexity

- Manual take over driving

- AVs limited to only some modes of transportation

- Difficulty of introducing AVs in the Czech Republic

All topics except (Dis)trust of manufacturers emerged in both analyses.

\section{Analysis of discussed topics}

\section{Time prediction for the development of AVs}

Predictions for how much time remains until the general availability of AV often appeared in discussions. The discussants usually did not state the reason for their estimates and simply stated the years. Between 15 and 30 years was most often mentioned. For example:

"Before all the bugs are worked out and it is put into real operation, and until it's been available for at least 10 years."

"So the prediction isn't that bad. Thirty years is the minimum if it continues at an ideal pace."
Reference: https://www.idnes.cz/ekonomika/doprava/ autonomni-vozy-pojistovny-zmeny.A180611 095011 ekodoprava in

There were more time predictions in the first analysis. The second analysis had estimations of a different nature. See below.

\section{Prediction based on negative experiences}

A large group of discussants could be described as skeptics. These discussants based their predictions on negative experiences. For example, there were negative assessments of the various means of driving assistance that are already in use today, including criticisms of automatic transmission, automatic high-beam headlights, and automatic braking. By analogy, these discussants believe that if these simple means of assistance do not work perfectly today, autonomous mobility will not be achievable in near future.

"And I'm not talking about the inexactness of radar cruise control. It's great for defensive driving in heavy traffic, but the fact that it breaks inconsistently or adds a burst of speed for overtaking is really annoying."

This group included discussants who called themselves experts or said they had experience in the field. However, it is not possible to prove if these claims true or if they were just an attempt to gain authority in the discussion. They usually reported skepticism and fear, given that they claim to know programming imperfections in practice.

"As an IT professional, on the other hand, I'm against any software controlling my car, house or life - because I know very well in practice how poorly most $S W$ is written and how manufacturers provide support and updates for their products."

Reference: https://auto.idnes.cz/diskuse.aspx?iddiskuse= A161127 211248 automoto vok

\section{Prediction based on analogy}

Another interesting category had contributions based on the analogy to aeronautical autopilot. Some debaters mentioned it in support of AVs.

"Autopilot, avoidance systems, and automatic landing are common parts of aircraft, and nobody makes a big deal out of it."

More often, however, it was used as an argument against AVs:

"The big difference is that planes don't need any pathways, they just need air to avoid the ground. There is air traffic control that makes sure you don't bump into each other (it's more complicated, it depends on the airspace class, rules, etc.). Finally, they are still not autonomous systems. There is still a pilot who is responsible, has to monitor all the systems, and has a number of tasks that the on-board systems cannot handle automatically."

In the second analysis, we observed the autopilot analogy was mentioned more often. Discussants also mentioned comparisons with trains, subways, and self-driving tractors.

"When simple things are much easier to manage autonomously - like trains, subways, trams - then it makes sense to me that it should progress to more complex structures. So far it can't do as much as a model railway."

Reference: https://www.idnes.cz/auto/zpravodajstvi/autonomni-auta-testovani-polygon-stribro accolade.A200122 211235 automoto $f d v$

\section{(Dis)trust of manufacturers}

This topic was mentioned only in the second analysis, and we include two subtopics that appeared. The first is to defend the future of AVs because they are in development by large companies that are likely to know what they are doing.

"... The fact that carmakers intend to invest tens of billions of euros into this would suggest that there will be some potential." 
Reference: https://www.idnes.cz/auto/zpravodajstvi/ autonomni-auta-testovani-polygon-stribro-accolade. A200122 211235 automoto $f d v$

The second subtopic is the distrust of these companies. Some discussants have begun to notice that manufacturers have been promising autonomous cars for some time and they are not fully fulfilling their promises. Other discussants distrusted the reported statistics of the minor accidents by tested AVs.

"Autonomous cars only drive where the operator chooses and where he thinks the algorithms will work for him, and only under good conditions. But a real driver drives everywhere under all circumstances, even where no one dares to allow an autonomous car. It doesn't go that fast either, and when it has a problem, it just gives up and stops. So any comparison of accidents is nonsense, you have nothing to compare, yet."

Reference: https://www.idnes.cz/auto/zpravodajstvi/autonomni-auta-testovani-polygon-stribro-accolade. A200122 211235 automoto $f d v$

\section{Driving pleasure}

Many discussants were against the introduction of AVs because driving is a pleasant activity. Some could imagine a compromise where they would drive only part of the trip. This view was opposed by a group who, on the contrary, saw the operation of the vehicle as tiring and would welcome rest. In both analyses, there was a concern that they might not have fun while driving. The first analysis also mentioned motion sickness. According to some discussants, being a passenger in an AV would have a worse effect than driving.

"It's hard if I don't want to feel sick. So all that's left is the squinting out of the window or sleep, which doesn't make much sense during the day, so boredom ..."

Reference: https://ekonomika.idnes.cz/diskuse.aspx? iddiskuse=A180611 095011 eko-doprava in

Especially in the second analysis, several could imagine what they would actually do in the car.

"You will not sleep. You will not do anything beneficial. If you wanted to do something like that, you would take the train."

Reference: https://www.idnes.cz/auto/zpravodajstvi/ autonomni-auta-testovani-polygon-stribro-accolade. A200122 211235 automoto $f d v$

\section{Questions arising from the use of AVs}

Discussants in both analyses very often pointed to the problem of different types of dilemmas. First, the legal questions. Who would be blamed for an accident - the driver or the manufacturing company? Some discussants see this discrepancy as almost intractable because they think that no company would want to take overall legal responsibility.

"A manufacturer wouldn't produce it if they were responsible and if the driver wouldn't take responsibility for the car if it killed someone."

Reference: https://www.idnes.cz/auto/zpravodajstvi/lidenechapou-autonomni-auta-podpora-od-ajtaku-tomu-nepomuze.A161127 211248 automoto vok

The biggest topic however, was the ethical/moral question. Who should to protect the car in the event of an unexpected accident?

"How would the moral dilemma - an unexpected obstacle at $80 \mathrm{~km} / \mathrm{h}$ - be solved if the car drives into a street light and kills a passenger or drives onto a sidewalk into children outside a kindergarten?"

Reference: http://www.auto.cz/autonomni-automobiloveprototypy-vykazuji-tisice-poruch-92094/diskuse?typ=1\&od= 37 Ekolik $=$ Esort $=$

In both analyses, there were opinions that the dilemma could not be resolved and that a person always decides better.
Several discussants resolutely refused to buy a vehicle that would not have its priority to protect the passengers.

"Sacrificing the passengers is unacceptable from my point of view."

"The idea that a car sacrifices me as a passenger doesn't seem acceptable to me at all. I just wouldn't buy a car like that."

Reference: http://www.auto.cz/autonomni-automobiloveprototypy-vykazuji-tisice-poruch-92094/diskuse?typ=1Eod= 37Ekolik=Esort=

\section{Risk of AV software infection}

Concerns about the misuse of AV, by hackers for example, emerged in the discussions. There were also voices that rejected this danger, arguing that "your phone has not been attacked by anyone yet." An interesting situation was outlined where the AV would stop at an obstacle set by criminals and the passenger would not be able to take control to escape.

"Certainly the police would make an effort to be able (within safety protocols, of course) to take remote control of the vehicle - but this would open up the opportunity for hackers who would be extremely attracted to this opportunity. Manufacturers will try to secure this, but don't we read every day about everything being breached / leaked / abused?"

Reference: https://www.autorevue.cz/pet-otazek-naautonomni-rizeni-na-ktere-zatim-nikdo-nema-odpoved/ ?showforum $=1$

\section{Joint operation}

How would fully autonomous cars operate in concert with non-autonomous cars? Some believed this was impractical and that $\mathrm{AV}$ would never be intelligent enough to take into account the unpredictability of human drivers or be able to decode the non-verbal signals of human drivers at an intersection. Others believed that, even with imperfections, AV would be safer than a human driver. Some suggested that only highway travel could be adapted for AV traffic.

"It probably never will be (figured out) off of the highway. When an unpredictable horse-drawn carriage is allowed on the road and (the horse) can be startled at any time ..."

"Otherwise we will have to wait until everyone has an autonomous car."

Reference: https://www.idnes.cz/auto/zpravodajstvi/lidenechapou-autonomni-auta-podpora-od-ajtaku-tomu-nepomuze.A161127 211248 automoto vok

AV that interacted with drivers who do not fully comply with traffic regulations was also a cause for concern. Many, especially in the first analysis, expressed the fear that AVs would be bullied by ordinary drivers. For example, they would not drive through an intersection on a green light until they had a completely clear path, which is common practice. This is a topic that has appeared repeatedly in the discussions and is unique for the Czech environment.

"How would it behave at a congested intersection? According to regulations, it could stand there for several hours."

Reference: https://www.autorevue.cz/autonomni-vozidla-budou-nebezpecna-a-nespolehliva-mysli-si-ridici/ ?showforum $=1$

\section{Carsharing}

Carsharing opened an interesting topic, particularly about parking at a destination. Some anticipated a reduction in transportation costs, although they believed that AVs would be more expensive to drive than conventional vehicles.

"Once autonomous driving is implemented, personal ownership of a car loses its meaning. It will be much cheaper and more convenient to use such a 'SuperUber', where you can call the car at any time with an 'app' on your mobile phone. In this case, the vehicles would be operated by the company 
and would be insured in the same way that trains, planes, and buses are insured today. "

Reference: https://ekonomika.idnes.cz/diskuse.aspx? iddiskuse=A180611 095011 eko-doprava jn

Of course, some could not imagine not owning a car and not having it immediately available at any time.

"Yeah, I can already see myself renting a car in the morning, dragging two child seats into it, going to kindergarten, school, work, and emptying the car to put it all into another car again in the afternoon. Nevertheless, the fact that almost all of us work and bring our kids to school at about the same time, it would probably be a battle every morning."

Reference: https://www.idnes.cz/auto/zpravodajstvi/lidenechapou-autonomni-auta-podpora-od-ajtaku-tomu-nepomuze.A161127 211248 automoto vok

\section{Financial complexity}

The topic of financial demands was closely connected to carsharing in the discussions. Some estimated the price of AVs would be very high and they were aware of the complexity of servicing cars that would have a lot of sensors. In the second analysis, a few people did not see the difference between current taxis and AVs, and they thought the price for a ride would be similar.

"It will not be a cheaper 'taxi' and it cannot be. The driver will not be sitting in the car, but he will be somewhere else. Someone would have to take care of it, its operation, and its security. The vehicle itself would be more expensive and it is quite wrong to assume that CZK 20 would cover the operation costs."

Reference: https://www.idnes.cz/auto/zpravodajstvi/ autonomni-rizeni-ridic-deloitte-kpmg.A200210 115642 automoto $f d v$

\section{Manual take over driving}

A frequently discussed topic was the degree of control for choosing the exact route and the ability of the driver to take over driving. The discussants had different ideas about how the operation of AV would take place and also about the (in)ability to manual takeover. Some saw AV as a completely independent unit where they could sleep during the journey, travel under the influence of addictive substances, transport a person without a driver's license, etc. These discussants approached this topic in a positive light. This topic again show a vague differentiation of discussants between automated and autonomous vehicles and between various levels of automation.

"Today, a person who, for some reason, cannot drive is often extremely disadvantaged compared to people who can drive. An autonomous car would be of great benefit to such a person."

Reference: http://www.auto.cz/autonomni-automobiloveprototypy-vykazuji-tisice-poruch-92094/diskuse?typ=1\&od= $\underline{37 \text { Ekolik=Esort }=}$

Others believe that AVs would, in some situations, require a manual takeover by a human driver (e.g., an emergency situation, driving on a dirt road, a complex situation, a breakdown, etc.). In this case, however, problems would arise, which the discussants themselves pointed out in both analyses. On the one hand, the driver would have to be constantly on the alert, because an emergency situation may require a response. There were opinions provided that a "non-driver" should not be behind the wheel, and that drivers who would likely predominantly use AV would be inexperienced and incompetent.

On the other hand, the possibility to switch to manual mode would be welcomed by people who like driving and people who are skeptical about handling complex driving situations with an AV.
"... What do you think a person who does not have enough experience will be able to do behind the wheel of an autonomous car that has had its autopilot fail? I don't think experience can really be gained from observation and without practice..."

Reference: https://zpravy.aktualne.cz/ekonomika/auto/ plne-autonomni-auto-je-utopie-rika-sef-firmy-ktera-v-jejich/ r 47ca921c13eb11e9a67dac1f6b220ee8/v diskuse/

\section{AV use limited only to some modes of transportation}

Another topic was the introduction of AVs only for certain modes, especially for freight transport and urban public transportion. The discussants in the second analysis mostly saw this as the first step where autonomous technologies would first adopt "simpler" driving, such as train transport or truck convoys on highways.

"Trucks and lorries will be the first to be put into service, but soon I expect to see only no-man trucks."

"Maybe public transport will be early. I can easily imagine it for trams."

Reference: https://www.svethardware.cz/anketa-nastavacas-autonomnich-vozidel/42704/diskuze

\section{Difficulty of introducing AVs in the Czech Republic}

Some discussants showed skepticism about the implementation of AVs into the Czech environment, particularly because of the quality of the Czech road infrastructure and the behavior of domestic drivers. They explained that the operation of AVs in the Czech environment will be difficult or even impossible. This opinion was more common in the second analysis.

"It's hard to imagine autonomous vehicles on Czech ... roads. In addition to AI, they would have to be equipped with a good dose of natural intelligence and true imagination."

Reference: https://www.autorevue.cz/autonomni-autato-tu-nebudou-mit-lehke-cesi-jim-veri-mene-nez-jinde/ ?showforum $=1$

\section{Concerns that arose from the analyzed topics:}

- Skepticism/fear for the (un)preparedness of AV technology for real-world operation

- Skepticism/fear of the intractability of moral and legal dilemmas

- Fear of attacks/crime

- Assistance would be required from a human driver who, as the user of AV, may have lost driving skills

- Insufficient quality of the infrastructure in the Czech Republic

- behavior of Czech drivers, who would create complex or impossible situations for the operation of AVs

- The interaction of AVs with manually driven vehicles - the suggestion that conentional vehicles would intimidate AVs that always follow the rules of the road

Contrary to expectations based on the surveys of public attitudes abroad, the fear of losing privacy and the fear of the misuse of personal data did not appear as explicit themes. On the contrary, the themes of the bullying of AVs by the drivers of normal cars and the difficulty of introducing AVs into the Czech Republic appeared.

\section{DISCUSSION}

The aim of this study was to use content analysis to identify main topics regarding autonomous vehicles discussed under news articles on the Czech Internet and to find out possible transformation of opinions through the time. In total, two analyses were performed, which included 17 discussion threads connected to articles on autonomous mobility. The 
overall effort of the discussants was to debate whether AVs would be a normal part of traffic. These estimates were often a reflection of discussants' concerns. It is worth mentioning that disccusants probably did not know the difference between automated and autonomous vehicles. Even in connected news articles terms were often exchanged. Therefore, opinions of various levels of automation took place in discussions and people understood the autonomous technology differently. It is understandable that general public and journalists do not have precise terminology. However, exchanging terms can produce misunderstanding which was often noticed.

Key topics were identified with a qualitative content analysis. A substantial part of extracted topics concerned predictions of the success of AVs. It is important to tell discussions were not moderated, therefore topics were presented and developed among discussants themselves. That is why some topics, for example interaction between drivers in AVs and pedestrians were not present. Because the discussion threads were on websites intended for the general public, we assume the vast majority of discussants were lay people. If a discussant attributed an expert role to himself, it could not be verified. We assumed that discussants were mostly "general public", but there was no way to verify our assumption which is one limit of our study.

Another finding is that between two analyses (2014-2018 and 2018-2020) there is no significant difference in discussed themes, despite only one new topic appeared in second analysis and that is (Dis)trust to manufacturers. The topic "Time prediction for the development of $A V \mathrm{~s}^{\prime \prime}$ consisted of predictions for the introduction of AVs into wider practice. Most of the estimates were made without additional argumentation, therefore can be concluded the discussants were non-professionals. The topic "Prediction based on negative experiences" mostly consisted of skeptical contributions by those who had had negative experiences with elements of control automation and where discussants extrapolated their negative experiences to the overall automation in transport. In this case, one can consider so-called technophobia or the fear of new emerging technologies that threaten established patterns of behavior, as an element in their arguments (Khasawneh, 2018). A study by Koul and Eydgahi (2020) confirmed the strong negative relationship of technophobia with the intention of using AVs. The topic "Prediction based on analogy" was extracted from contributions in which the discussants used the AV analogy for other modes of transport, such as air transport. The overall message of these contributions was negative, as the discussants pointed to air transportation as many times safer and more secure when compared to transport by road vehicles. The topic of "(Dis)trust of manufacturers" reflected skepticism about the introduction of AV into widespread use due to long-unfulfilled promises of the automotive concerns. "Driving pleasure" topic consisted of contributions from discussants who enjoy driving and who are not willing to switch to autonomous mobility. These comments could reflect the findings of studies that examined the relationship between Locus of Control (LoC) and driving, which confirmed the fact that people with internal LoC prefer to drive a car and are therefore less likely to adopt AVs, and people with external LoC do not have confidence in their ability to drive and therefore would leave control to AVs (Rudin-Brown \& Noy, 2002; Stanton \& Young, 2007). Because of impossibility to identify discussant's other characteristics we can only assume if this is the case or not. "Manual take over driving" topic partially overlaps with the previous one, because some of the contributions mentioned $\mathrm{AV}$ as a solution for non-drivers and individuals who are stressed by driving. At the same time, drivers who enjoy driving would not hand over control to an AV. Furthermore, the issue of handing over the control of AV to artificial intelligence and back was addressed in the same topic, where the insufficient ability of the discussants to assess the issue was manifested. The topic "Questions arising from the use of $A V^{\prime \prime}$ consisted of contributions that concerned the ethical and legal liability for traffic accidents involving an AV, it also follows that the discussants were not able to assess it well. The topics "Financial complexity", "Joint Operation", "Carsharing" and "AV limited only to some modes of transportation" pointed to the same fact: the ignorance of the topic. Compared to foreign research, the topics of the loss of privacy and the misuse of personal data did not appeared, which is probably due to a different cultural environment. In the US, intensive discussions on personal data protection are currently taking place.

It is important to mention that topics of discussions reflected themes of linked news articles. Therefore we presume this is the reason why other topics from research had not emerged. For example topics like interaction between autonomous vehicles and pedestrians like in Rasouli and Tsotsos (2020) or topics concerning data privacy were not present because news articles did not mention these themes. Although disscussants mentioned other topics, they rarely touched different themes than themes of news articles. The overall tone of analyzed contributions in both analyses is rather negative. Because AVs are new technology, it is clear the general public does not have sufficient understanding of the issue. Therefore misunderstanding and lack of experience with topics in question results in evalution based on attitudes of individuals stemming from emotional evalution of topic at the expense of evidence-based evalution. Negative attitudes towards AV can also be caused by cultural differences. Hudson, Orvisk, and Hunady (2019) examined the attitudes of public within the individual states of the European Union where there are significant differences. However, overall public attitude within the EU skews negatively. Furthermore, most of the research and pilot operations of AVs are being conducted in the US which is another possible explanation for the inability of these discussants to grasp the issue.

Socio-demographic variables play an important role in attitudes towards AVs and possibly in related concerns. Studies have shown positive attitudes of university-educated individuals from large cities towards AVs and negative attitudes of less educated people from rural areas (Lavieri, Garikapati, Bhat, Pendyala, Astroza, \& Dias, 2017; Saeed, Burris, Labi, $\&$ Sinha, 2020). Higher levels of education predict a positive attitude towards AVs and men prefer AVs more than women (Pakusch, Stevens, Boden, \& Bossauer, 2018; Payre, Cestac, $\&$ Delhomme, 2014). Unfortunately, the nature of the discussion threads did not allow us to obtain any absolute sociodemographic variables on a usable scale. The analysis took place on well-known news websites not on social networks, so the discussion posts could only be analyzed as that of the specific demographic group. Other studies used different methods including face-to-face interviews like Hudson et al. (2019) with description of socio-demographic variables. We based our inference on body of research concerning sociodemographic variables of internet users. Research by Kalogeropoulos (2019) pointed to the fact that people under the age of 35 use social networks to get news not the classic news portals that are preferred by the older generation. We believe negative attitudes and concerns may exist for the older users of the selected news portals, which would be, in accordance with previous research, matched by a reluctance to accept AVs. Unfortunately, without socio-demographic data, this is not possible to infer and selected contributions may not be representative for the Czech population.

There are many theoretical models in professional sources to explain the preference for acceptance and potential use of AVs, especially the so-called Theory of Planned Ac- 
tion. This model has been used in studies to focus on user behavior when using carsharing or electric vehicles (Moons \& De Pelsmacker, 2015; Wang, Wang, Wang, Wei, \& Wang, 2020). Planning theory explains the acceptance of AV users as the sum of several factors, including their attitudes towards autonomous mobility, subjective norms, and their perceived control over the decision to use AVs (Ajzen, 1991; Acheampong \& Cugurullo, 2019). A study by Yuean, Chua, Wang, Ma, and Li (2020) used the Planned behavior theory to identify the key perceptions of autonomous mobility as the following: a mode of transport that offers advantages over conventional cars; the perceived compatibility of AV with the respondent's lifestyle; and the hedonic motivation that influences attitudes toward AV. The perceived complexity of use has a negative impact on the attitude towards AVs. Subjective norms and perceived control over the decision to use AVs also have a key influence. All three components have a positive effect on AV acceptance (Yuen, Chua, Wang, Ma, \& Li, 2020).

In light of the theory of planned action, previous research and the results obtained from the discussions, it can be concluded that users who have a positive attitude towards AVs, in accordance with their subjective norms and ability to use AVs, will accept and use it. Across topics, in particular, a positive attitude towards autonomous mobility, independent of the concerns of others, has led positive users to become early adopters. Furthermore, it can be stated that positive discussants perceived autonomous mobility as more advantageous than classical mobility. On the other hand, the perceived complexity was an obstacle for discussants who did not believe in autonomous mobility. However like in case of Locus of Control, we could not obtain personal characteristics, we can only make assumptions.

One of the original intentions of this study was to bridge the shortcomings of data collection by using online questionnaires. On the other hand, our methodology could not assess socio-demographic variables which made it impossible to demonstrate the representativeness of the data. Furthermore, the selection of the discussion threads from news portals and not social networks could lead to demographic bias because every webpage hase its own demographics.

The overall output of this study is that discussants on the large Czech news portals have a large number of concerns about autonomous mobility and they are generally negative about it. Future research should focus on better control for the socio-demographic variables and include an analysis of the contributions within social networks to better capture the views of the Czech public, and the possible creation of materials for a general educational campaign focused on AV. As part of the educational campaign, emphasis should be placed on presenting the advantages of autonomous mobility over conventional transport, because the perception of AVs as a more advantageous mode of transport leads to a positive public attitude. Furthermore, highlighting the positive features of $\mathrm{AV}$, such as increased safety, reduced costs, reduced driving time, increased comfort, the increased possibility of using AVs for the disabled and non-drivers, and the ability to use time while driving for work or entertainment can significantly affect acceptance in a positive direction. Campaigns should also aim to reduce the perception of autonomous mobility as complex and generally complicated modes of transportion so that pilot operations of AVs can be carried out to convince the mainly the negative population (i.e., the older generation, people with less education). It is especially important because tasks and behavior perceived as simple leads to bigger probability of chosing behaviour in question (Patall, Sylvester, \& Han, 2014). Other topics like ethics could be adressed as well but focus of future education campaigns should mirror topics discussed in Czech population. For ex- ample, if ethics of using AVs is not important topic for Czech population it should not be addressed in campaign. It is important, of course, to express support within the campaign, especially from the representatives of local governments and state institutions.

Our analysis of internet discussions pointed out several topics which could be further examined. Future research could use methodology like questionnares and focus groups. More so future research has to obtain socio-demographic variables to thoroughly examine specific brackets of Czech population and their attitudes towards AVs. Important concerns like general skepticism towards AV, fear of cyberattacks, declining drivers skills while using AVs, needed assistance from human drivers, insufficient infrastructure and interaction with human drivers are possible directions of future research. Other topics like using AVs by non-drivers are also possible directions of future research.

\section{Acknowledgements}

This article was produced with the financial support of the Ministry of Transport within the programme of longterm conceptual development of research institutions on the research infrastructure acquired from the Operation Programme Research and Development for Innovations (CZ.1.05/2.1.00/03.0064).

\section{REFERENCES}

AAA Newsroom. (2018). AAA: American Trust in Autonomous Vehicles Slips [Online]. Retrieved May 02, 2020, from https://newsroom.aaa.com/2018/05/aaa-american-trustautonomous-vehicles-slips/

Acheampong, R. A., \& Cugurullo, F. (2019). Capturing the behavioural determinants behind the adoption of autonomous vehicles: Conceptual frameworks and measurement models to predict public transport, sharing and ownership trends of selfdriving cars. Transportation Research Part F: Traffic Psychology And Behaviour, 62, 349-375.

Ajzen, I. (1991). The theory of planned behavior. Organizational Behavior And Human Decision Processes, 50(2), 179-211.

Bansal, P., Kockelman, K. M., \& Singh, A. (2016). Assessing public opinions of and interest in new vehicle technologies: An Austin perspective. Transportation Research Part C: Emerging Technologies, 67, 1-14.

Deloitte. (2019). 2019 Global Automotive Consumer Study: Consumer trends in the automotive industry.

Doyle, B. (2016). 5 Reasons Why Google Glass was a Miserable Failure [Online]. Retrieved April 05, 2020, from https://www.business2community.com/tech-gadgets/5reasons-google-glass-miserable-failure-01462398

Flinders, K. (2017). Brits expect driverless cars to outnumber normal cars in 15 years [Online]. Retrieved November 02, 2020, from https://www.computerweekly.com/news/450419079/Britsexpect-driverless-cars-to-outnumber-normal-cars-in-15-years

Gabrhel, V., Ježek, S., \& Havlíčková, D. (2019). Public opinion on connected and automated vehicles: the Czech context. Transactions On Transport Sciences, 10(2), 42-52.

Gao, P., Hensley, R., \& Zielke, A. (2014). A road map to the future for the auto industry. McKinsey Quarterly

Hudson, J., Orviska, M., \& Hunady, J. (2019). People's attitudes to autonomous vehicles. Transportation Research Part A: Policy And Practice, 121, 164-176.

Kalogeropoulos, A. (2019). How Younger Generations Consume News Differently [Online]. Retrieved October 29, 2020, from https://www.digitalnewsreport.org/survey/2019/how-youngergenerations-consume-news-differently/

Kelley, K., Clark, B., Brown, V., \& Sitzia, J. (2003). Good practice in the conduct and reporting of survey research. International Journal for Quality in health care, 15(3), 261-266. 
Kilian, T., Hennigs, N., \& Langner, S. (2012). Do Millennials read books or blogs? Introducing a media usage typology of the internet generation. Journal of Consumer Marketing, 29(2), 114-124.

Khasawneh, O. Y. (2018). Technophobia without boarders: The influence of technophobia and emotional intelligence on technology acceptance and the moderating influence of organizational climate. Computers In Human Behavior, 88, 210-218.

König, M., \& Neumayr, L. (2017). Users' resistance towards radical innovations: The case of the self-driving car. Transportation Research Part F: Traffic Psychology And Behaviour, 44, 42-52.

Koul, S., \& Eydgahi, A. (2020). The Impact of Social Influence, Technophobia, and Perceived Safety on Autonomous Vehicle Technology Adoption. Periodica Polytechnica Transportation Engineering, 48(2), 133-142.

Kyriakidis, M., Happee, R., \& de Winter, J. C. F. (2015). Public opinion on automated driving: Results of an international questionnaire among 5000 respondents. Transportation Research Part F: Traffic Psychology And Behaviour, 32, 127-140.

Lavieri, P. S., Garikapati, V. M., Bhat, C. R., Pendyala, R. M., Astroza, S., \& Dias, F. F. (2017). Modeling Individual Preferences for Ownership and Sharing of Autonomous Vehicle Technologies. Transportation Research Record: Journal Of The Transportation Research Board, 2665(1), 1-10.

Li, T., Lin, L., Choi, M., Fu, K., Gong, S., \& Wang, J. (2018). YouTube AV 50K: An Annotated Corpus for Comments in Autonomous Vehicles. 2018 International Joint Symposium On Artificial Intelligence And Natural Language Processing (Isai-Nlp), 1-5.

McFadden, C. (2017). Concorde: The Real Reason Why the Supersonic Passenger Jet Failed [Online]. Retrieved April 06, 2020, from https://interestingengineering.com/concorde-thereal-reason-why-the-supersonic-passenger-jet-failed

Moons, I., \& De Pelsmacker, P. (2015). An Extended Decomposed Theory of Planned Behaviour to Predict the Usage Intention of the Electric Car: A Multi-Group Comparison. Sustainability, 7(5), 6212-6245.

Nielsen, T. A. S., \& Haustein, S. (2018). On sceptics and enthusiasts: What are the expectations towards self-driving cars? Transport Policy, 66, 49-55.

Pakusch, C., Stevens, G., Boden, A., \& Bossauer, P. (2018). Unintended Effects of Autonomous Driving: A Study on Mobility Preferences in the Future. Sustainability, 10(7).

Patall, E. A., Sylvester, B. J., \& Han, C. -woo. (2014). The role of competence in the effects of choice on motivation. Journal Of Experimental Social Psychology, 50, 27-44. https://doi. org/10.1016/i.jesp.2013.09.002

Payre, W., Cestac, J., \& Delhomme, P. (2014). Intention to use a fully automated car: Attitudes and a priori acceptability. Transportation Research Part F: Traffic Psychology And Behaviour, 27, 252-263.

Rasouli, A., \& Tsotsos, J. K. (2020). Autonomous Vehicles That Interact With Pedestrians: A Survey of Theory and Practice [Online]. Ieee Transactions On Intelligent Transportation Systems, 21(3), 900-918. https://doi.org/10.1109/TITS.2019.2901817

Rudin-Brown, C. M., \& Noy, Y. I. (2002). Investigation of Behavioral Adaptation to Lane Departure Warnings. Transportation Research Record: Journal Of The Transportation Research Board, 1803(1), 30-37.

Saeed, T. U., Burris, M. W., Labi, S., \& Sinha, K. C. (2020). An empirical discourse on forecasting the use of autonomous vehicles using consumers' preferences. Technological Forecasting And Social Change, 158.

SAE. (2019). SAE Standards News: J3016 automated-driving graphic update [Online]. Retrieved October 16, 2020, from https://www.sae.org/news/2019/01/sae-updates-j3016automated-driving-graphic

Schoettle, B., \& Sivak, M. (2014a). A survey of public opinion about connected vehicles in the U.S., the U.K., and Australia. 2014 International Conference On Connected Vehicles And Expo (Iccve), 687-692.
Schoettle, B., \& Sivak, M. (2014b). Public opinion about self-driving vehicles in China, India, Japan, the U.S., the U.K., and Australia. Michigan: University of Michigan: Transportation Research Institute

Smith, A., \& Anderson, M. (2017). Automation in Everyday Life. Washington, D.C.: Pew Research Center

Stanton, N. A., \& Young, M. S. (2007). Driver behaviour with adaptive cruise control. Ergonomics, 48(10), 1294-1313.

van Arem, B., van Driel, C. J. G., \& Visser, R. (2006). The Impact of Cooperative Adaptive Cruise Control on Traffic-Flow Characteristics. Ieee Transactions On Intelligent Transportation Systems, 7(4), 429-436.

Wang, Y., Wang, S., Wang, J., Wei, J., \& Wang, C. (2020). An empirical study of consumers' intention to use ridesharing services: using an extended technology acceptance model. Transportation, 47(1), 397-415.

Wright, K. B. (2005). Researching Internet-Based Populations: Advantages and Disadvantages of Online Survey Research, Online Questionnaire Authoring Software Packages, and Web Survey Services. Journal Of Computer-Mediated Communication, 10(3).

Yuen, K. F., Chua, G., Wang, X., Ma, F., \& Li, K. X. (2020). Understanding Public Acceptance of Autonomous Vehicles Using the Theory of Planned Behaviour. International Journal Of Environmental Research And Public Health, 17(12).

\section{APPENDIX A - LINKS TO ARTICLES WITH RELEVANT DISCUSSIONS}

First Analysis (2014 - 2018)

https://www.autorevue.cz/autonomni-vozidla-budou-nebezpecnaa-nespolehliva-mysli-si-ridici

https://www.auto.cz/autonomni-automobilove-prototypyvykazuji-tisice-poruch-92094

https://www.svethardware.cz/anketa-nastava-cas-autonomnichvozidel $/ 42704$

https://www.idnes.cz/auto/zpravodajstvi/lide-nechapouautonomni-auta-podpora-od-ajtaku-tomu-nepomuze. A161127 211248 automoto vok

https://www.autorevue.cz/pet-otazek-na-autonomni-rizeni-naktere-zatim-nikdo-nema-odpoved

https://www.autorevue.cz/skupina-pravniku-chce-dostatautonomni-vozy-na-ceske-silnice

https://www.idnes.cz/ekonomika/doprava/autonomni-vozypojistovny-zmeny.A180611_095011_eko-doprava_jn

Second Analysis (2018 - 2020)

https://www.idnes.cz/auto/zpravodajstvi/autonomni-vuzroboticke-rizeni.A181120 181958 automoto fdv

https://zpravy.aktualne.cz/ekonomika/auto/plne-autonomniauto-je-utopie-rika-sef-firmy-ktera-v-jejich/r 47ca921c13eb11e 9a67dac1f6b220ee8/

https://www.penize.cz/doprava/403271-ztratime-svobodu-ridit-auto https://www.autorevue.cz/autonomni-vozidla-nejsou-tak-dalekobritanie-uz-muze-testovat-bez-ridicu

https://www.autorevue.cz/kolona-autonomnich-vozu-v-cine-sivyslouzila-svetovy-rekord-za-sebou-jelo-55-aut

https://elektrickevozy.cz/clanky/jak-tesla-uci-sva-auta-abymyslela-jako-lide\#comments

https://zpravy.aktualne.cz/ekonomika/auto/autonomni-autabudou-lide-chtit-rozsiri-se-jako-mobily-veri/r f9505e8211b911 ea84260cc47ab5f122/

https://www.idnes.cz/auto/zpravodajstvi/contridromautonomni-vuz-budoucnost-doprava-bezpecnost-mercedes. A190107 132452 automoto taj

https://www.idnes.cz/auto/zpravodajstvi/autonomni-auta-testovanipolygon-stribro-accolade.A200122 211235 automoto fdv

https://www.idnes.cz/auto/zpravodajstvi/autonomni-rizeni-ridicdeloitte-kpmg.A200210_115642_automoto_fdv 